\title{
Aging and Reproduction in Social Insects - A Mini-Review
}

\author{
Jürgen Heinze Alexandra Schrempf \\ Biologie I, Universität Regensburg, Regensburg, Germany
}

\section{Key Words \\ Longevity $\cdot$ Reproductive success $\cdot$ Senescence . \\ Caste dimorphism $\cdot$ Social insects, ants}

\begin{abstract}
Perennial social insects are characterized by the extraordinarily long lifespan of their reproductive females, which may be tens or hundreds of times larger than that of non-social insects of similar body size and also greatly surpasses that of conspecific non-reproductives. Evolutionary theories of aging explain this phenomenon from the low extrinsic mortality queens experience once they have successfully established their colony. The aim of our review is to summarize recent findings on the ultimate and proximate causes of increased queen longevity in social insects, in particular ants and honey bees. While progress is being made in elucidating the interrelations between the vitellogenin, juvenile hormone, fecundity, and senescence, we feel that the explanation for the comparatively short lifespan of queens in multiqueen societies is as yet not satisfactory and needs further attention, both concerning its proximate and ultimate basis.
\end{abstract}

Copyright $\odot 2008$ S. Karger AG, Basel

\section{Bees, Ants, and Termites Are Long-Lived - So What?}

Social insects are well known for their ecological dominance, the complexity of their behaviors and life histories, and, of course, their reproductive division of labor [1]: only the queens (and in termites also the kings) repro- duce, whereas most other individuals, the workers, are usually sterile and help rearing the offspring of the queen (fig. 1). In the last decade, however, researchers have started to focus on yet another puzzling trait of social insects: their often extraordinarily long lifespans. It might come as a shock to non-specialists that several unwelcome house or garden pests may easily outlive their beloved pet cats and dogs: the queens of many species of perennial social insects, in particular ants and termites, may live for up to 30 years [1-3], which is two to three orders of magnitude more than the lifespan of many notoriously ephemeral solitary insects, such as mayflies or mosquitoes, and even considerably longer than other comparatively longlived taxa, such as dragonflies and some beetles [4].

In addition, the lifespan of social insects may vary tremendously within species, and this variation goes against the normally observed life history tradeoff between reproduction and longevity $[5,6]$. Whereas in such diverse animals as fruit flies, nematodes, mice and humans, elevated reproductive rates are associated with an average reduced survival, the queens of perennial social insects usually have a much longer lifespan than their workers. This difference is most pronounced in species with a marked caste dimorphism, such as honey bees and most ants. Queens and workers generally do not differ in genotype but can be remarkably distinct in gene expression patterns, size, ontogeny, physiology, diet, and activity, and all these interwoven factors presumably contribute to the difference in longevity [1-3]. However, a considerable extension of lifespan has also been documented for reproductives of those species in which the two functional

\section{KARGER \\ Fax +4161306 1234 \\ E-Mail karger@karger.ch}

www.karger.com
(C) 2008 S. Karger AG, Base

0304-324X/08/0543-0160\$24.50/0

Accessible online at:

www.karger.com/ger
Prof. Dr. Jürgen Heinze

Biologie I, Universität Regensburg, Universitätsstrasse

DE-93040 Regensburg (Germany)

Tel. +49941943 3054, Fax +499419433304

E-Mail juergen.heinze@biologie.uni-regensburg.de 

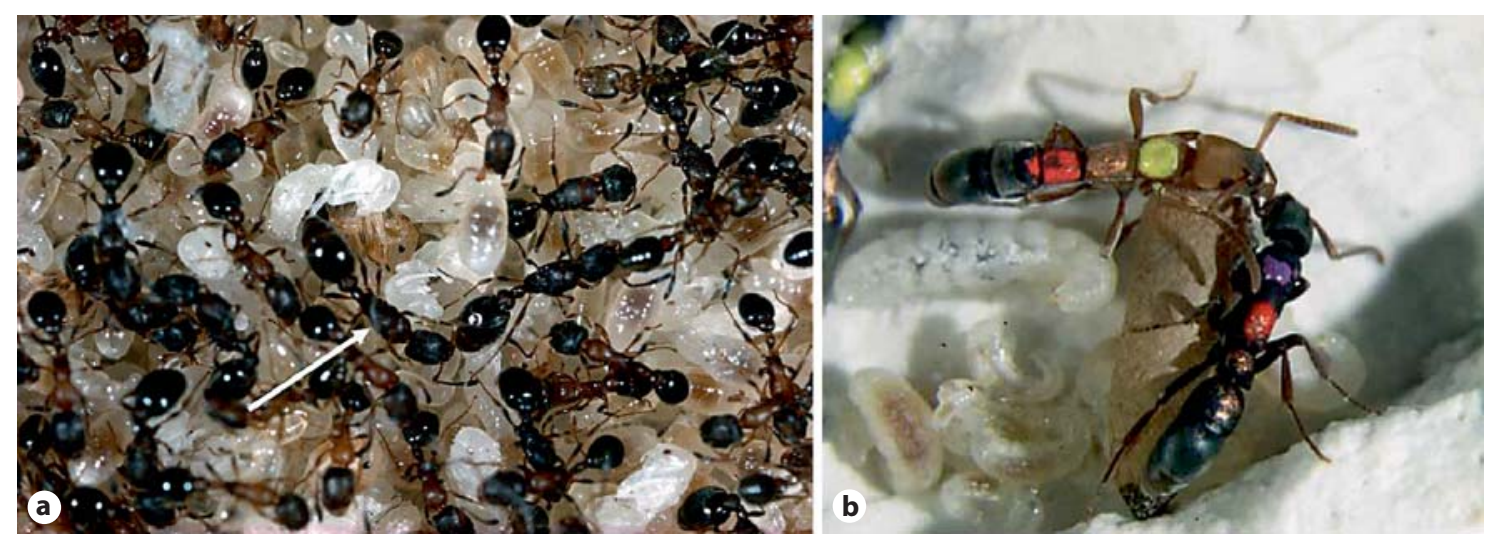

Fig. 1. a Detail of a nest of the ant Cardiocondyla mauritanica. The arrow points to one of the many queens, which are characterized by larger body size, a broader thorax, darker coloration and are specialized for laying eggs, whereas the more slender, smaller workers take over all the non-reproductive tasks in the society. As in other ant species, queens may live considerably longer than the workers, though they do not differ genetically and develop from the same female larvae. $\mathbf{b}$ Dominance interaction among two in- dividually marked workers of the ant Platythyrea punctata, with the dominant (on top) violently antennating the crouching subordinate. In P. punctata, all workers are in principle capable of producing female offspring from unfertilized eggs (thelytokous parthenogenesis), but only the highest ranking individual in the hierarchy actually does so. This individual outlives its non-reproductive nestmates, inspite of being identical to the latter in morphology, ontogeny, and genetics. Photo by Anne Hartmann. castes are morphologically identical and differ only in social or reproductive status $[7,8]$. In addition, mating itself appears to prolong the life of queens even when fecundity is not affected [9].

The patterns of aging in social insects have therefore become of considerable interest both for researchers studying the ultimate, i.e., evolutionary causes of variation in longevity and those analyzing the proximate, i.e., genomic, cellular, and physiological mechanisms involved in aging and senescence. The aim of this review is to highlight some recent advances in our understanding of aging in social insects and to critically examine the evidence that extrinsic mortality determines the evolution of lifespan. We will focus in particular on the two female castes, queens and workers, in ants and honey bees, as most current research is concentrating on aging in these perennial social Hymenoptera rather than termites.

\section{Evolutionary Theories of Aging Can Explain Why Queens Outlive Workers}

In evolutionary theories of aging and longevity, senescence is a non-adaptive consequence of the strength of selection declining with increasing age, which leads to the accumulation of late-acting, deleterious mutations that may ('mutation accumulation') or may not ('antagonistic pleiotropy', 'disposable soma'; table 1) have a positive in- fluence on fitness earlier in life [10]. Obviously, the higher the rate of age-independent extrinsic mortality due to predation, parasitism, pathogens, or stressful abiotic conditions, the faster will mutations with negative consequences later in life build up, because most individuals will have reproduced, passed on copies of their genes to their offspring, and died from external causes before the harmful effects of these mutations become manifest. In other words, organisms that are exposed to the highest rates of environmentally imposed mortality will age fastest. Evolutionary theories therefore give appealing answers to the questions why we senesce and why we die, but though they are supported by the results of laboratory selection experiments, it is still debated whether they are indeed fully validated and can replace other, more mechanistic models $[11,12]$. The application of evolutionary theories to social insects appears to provide a straight forward and simple explanation for the difference in life expectancy between queens and workers and also for the variation among individuals within the two female castes $[3,13]$.

The unusual life history of perennial social insects provides individuals with different tasks, which are associated with different time courses of extrinsic mortality. Queens of many ant species have an extremely high risk of dying in early adult life. After leaving the relative safety of their maternal nests, young queens are exposed to strong predation during their mating and dispersal flights, and in addition to parasitism and bacterial and fungal 
Table 1. Schematic illustration of the various evolutionary theories on aging, their consequences on lifespan variation, and the observed phenomena in social insects

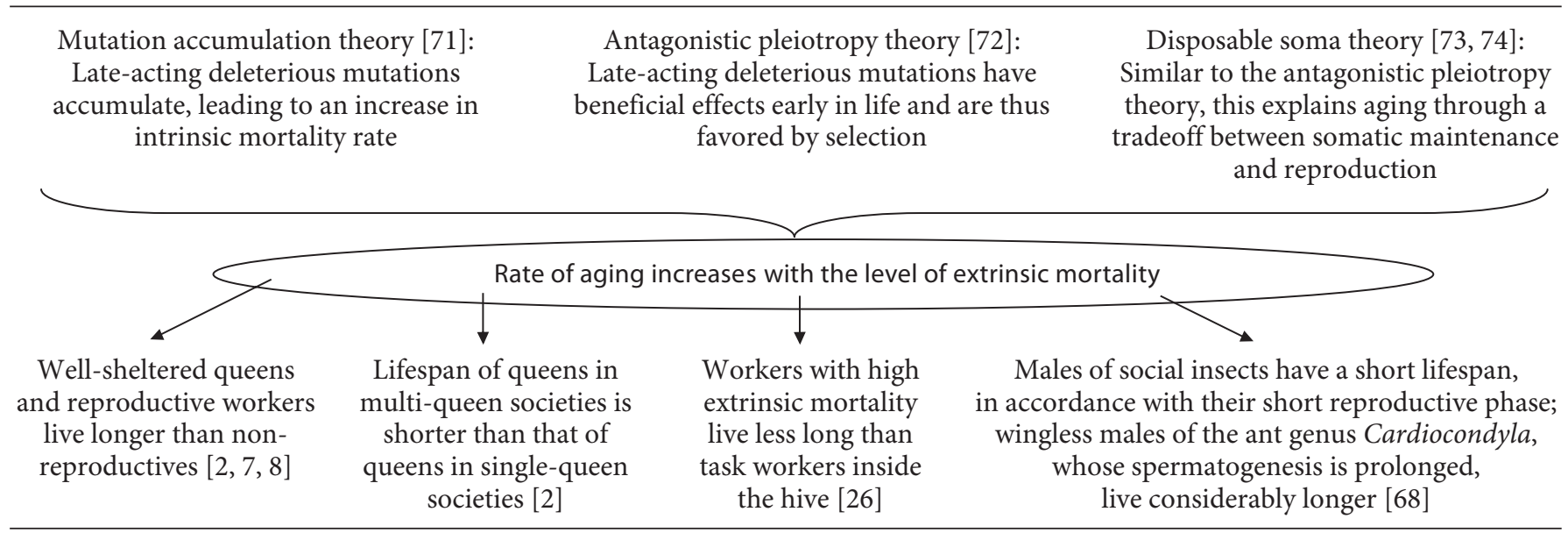

pathogens when they found new societies on their own [1]. Furthermore, because they do not re-mate later in life, queens have to store large quantities of sperm for the fertilization of eggs throughout their lives, which shortly after mating appears to be associated with considerable immunity costs [14]. It has been estimated that in some ant species less than $1 / 1,000$ of the young queens survive to produce their own sexual offspring [1]. Building up the large workforce needed to establish a prospering society that produces new sexuals may take several years, but once queens have achieved this stage, they are well sheltered by their workers from environmental hazards and their extrinsic mortality becomes very low. The workers take over all risky duties, such as foraging, nest guarding, and defense, while the queens can concentrate on reproduction and increase their reproductive success from year to year. Obviously, the long duration of the founding phase, during which queens produce only non-reproductive workers, requires them to be rather long-lived [4, 12], but that queens may live on for many years after producing the first sexual offspring strongly supports the idea that, as predicted by evolutionary theories, low extrinsic mortality is associated with an extension of lifespan $[2,3,13]$.

If queens are considered as a superorganismic analog of the valuable germ cells of multicellular organisms, the workers clearly show all the qualities of a 'disposable soma'. Though both castes equally develop from fertilized eggs and as often differ only in reproductive and social status, honey bee and ant workers rarely reach the lifespan of queens but instead die within a few weeks, months, or years even when shielded from predation in laboratory colonies [1-3]. Evolutionary theories of aging attribute this to the normally extraordinary costs and mortality risks of foraging. For example, $98 \%$ of all honey bee workers are believed to die outside the hive from predation, desiccation, or pathogens [15], and foragers of the desert ant Cataglyphis bicolor have a life expectancy of less than 1 week because of predation by spiders and robber-flies [16]. The division of labor among workers often follows an age polyethism in which young individuals perform all duties in the relative safety of the nest, while older individuals take over tasks outside the nest [1]. This pattern of age-based division of labor is clearly more costeffective [17] than the reverse arrangement in human societies, in which young individuals with the highest future life expectancy may be forced to engage in tasks with particularly high mortality risk, e.g., warfare.

Research in particular in honey bee workers documents that intrinsic mortality and external risks are intricately linked. On the one hand, age at first flight appears to be critically important: senescence can be delayed or speeded up by preventing workers from leaving the nest or forcing them to do so earlier [18]. Hive bees, which are prevented from foraging, can live over eight times longer than foragers $[15,18,19]$, and non-flying winter bees in the 'diutinus stage' can live up to 8 months $[19,20]$. Senescence obviously starts with foraging: workers show a decline in physiological resistance to stress, such as heat, desiccation, and starvation [21] and their hemocyte count drops [22], while their behavioral performance appears to remain unchanged [23]. On the other hand, an experimental increase in intrinsic mortality 
by exposing honey bee or ant workers to $\mathrm{CO}_{2}$ or other stressors leads to precocious foraging $[24,25]$, i.e., the highly plastic course of behavioral ontogeny can be manipulated by changing the internal status.

In worker-polymorphic ants, in which different size classes of workers engage in different tasks in or outside the nest, lifespan again varies with task-specific extrinsic mortality. Large workers of the weaver ant Oecophylla smaragdina engage in risky foraging, while the smaller nurses remain in the relative safety of the nest and take care of the brood. Even without predation in laboratory colonies, large workers have a shorter lifespan than small workers [26]. Similar results have been found in leaf-cutting ants [27] - in contrast to the common trend that, across animals, larger body size is associated with a longer lifespan [5].

\section{Queens in Multi-Queen Societies Have Shorter Lifespans}

While all these results are in full agreement with the hypothesis that the evolution of social insect lifespans is mainly driven by extrinsic mortality rate, the phenomenon of the shortened lifespan of queens in multi-queen colonies needs further investigation. In particular in ants, the nests of many species may contain multiple queens (polygyny). New societies of such polygynous species and also of several single-queen (monogynous) species are founded in a process called swarming or budding, in which workers from the maternal nest assist a young freshly mated queen during dispersal and colony founding. In a somewhat similar process, a honey bee queen and many of her workers may emigrate and start a new nest, allowing a daughter of the old queen to take over the established hive. In this way, new colonies are initiated much safer and faster than by independent founding of solitary queens, and the reproductive success of queens depends much less on age than in monogynous species. Dependently founding queens are less likely to be killed by predators than dispersing and solitarily founding queens, and from the very beginning of their new colonies they are assisted, cared for, and provided with food by workers. Queens of polygynous species have a much shorter lifespan than queens of related monogynous species $[2,3,28]$. Keller and Genoud [2] explained this in accordance with evolutionary theory from the assumedly higher mortality risk of queens of polygynous ant species: indeed, some of these species opportunistically inhabit fragile nests, which rapidly decay. They are thus frequently forced to move to new nest sites, and predation or abiotic stress during nest relocation might increase the extrinsic mortality [29].

However, other polygynous species inhabit rather permanent nests underground or stable mounds and do not frequently move. Nevertheless, the lifespan of their queens is typically lower than in related monogynous species, as exemplified by two mound-building wood ants with similar life histories, polygynous Formica polyctena and monogynous Formica exsecta, with queen lifespans of 5 and 20 years, respectively [3]. Furthermore, the actual mortality risk of queens in frequently moving species has as yet not been determined. We therefore feel that alternative explanations for the lifespan difference between single- and multi-queen species need to be explored. For example, polygyny is often associated with r-selection, i.e., the maximization of population growth rates [30]. Queens from polygynous species might therefore have a shorter lifespan than those of their independently founding sibling species either because of a tradeoff between early reproduction and lifespan or because selection for a long lifespan is relaxed [31]. Fitness-relevant reproduction, i.e., the production of virgin queens and males, starts considerably earlier in polygynous than monogynous societies, but two observations speak against the tradeoff hypothesis: queens are normally not in control of the caste fate of their offspring, and the production of large numbers of queen-destined eggs does not exhaust the resources of a queen more than laying large numbers of worker-destined eggs. Furthermore, queens in polygynous societies usually are less fertile than queens in monogynous societies - the traditional tradeoff between reproduction and longevity is thus expected to lead to queens being more long-lived in polygynous than in monogynous societies. The second explanation may instead be more applicable. Models suggest that kin selection can lead to the evolution of a shorter deterministic lifespan when offspring dispersal is limited [32] and the latter is definitively the case in polygynous social insects. However, the exploration of the role of kin-selected effects on aging has only recently begun and has not yet been fully applied to perennial social insects [33].

Given that queens of the ant Cardiocondyla obscurior from identical laboratory stock colonies exhibited pronounced differences in lifespan when randomly assigned to live in monogynous or polygynous societies [Schrempf A, Cremer S, and Heinze J, unpublished], queen longevity appears to be a naturally plastic trait that responds to the social environment. Whether in this case queenqueen or queen-worker antagonism might be involved is as yet not clear, but kin conflict in insect societies may in 
general be associated with increased queen mortality [33]. For example, every spring workers kill $90 \%$ of all queens in polygynous nests of the Argentine ant, Linepithema humile [34], and in the ant Leptothorax gredleri, fighting among nestmate queens regularly leads to injuries and perhaps also death [35]. Evidently, the phenomenon of lifespan differences between queens from monogynous and polygynous societies is embedded in the more general life history problem of the evolution of semelparity and iteroparity (single vs. repeated reproduction) and requires further analyses.

\section{Mating and Reproduction Boost the Lifespan of Female Reproductives}

As mentioned above, one of the most fundamental tradeoffs in theories on life history evolution is that between lifespan and reproductive effort. Increased reproductive effort is usually associated with a shortened lifespan throughout invertebrates and vertebrates - perennial social insects and the highly social mole-rats [36] are striking exceptions to this rule. In solitary animals, several factors contribute to the shortened lifespans of reproductively active animals. First, resources are finite and individuals have to allocate them between somatic maintenance and reproduction. Second, the act of mating itself may be associated with costs in particular for females. Males of many species have been shown to injure or poison their mates during copulation and thus force them to increase their immediate reproductive effort (from which the present male directly benefits) at the cost of future life time and reproductive success (from which another male might benefit, because females are rarely strictly monogamous). The resulting conflict between females and males has apparently led to an arms race resulting in more and more complex manipulations, genital armatures, and seminal fluids [37].

Because of the special life history of social insects, in which females store all sperm obtained from one or several males during a short mating period in early adult life and use it to fertilize worker-destined eggs first and queen-destined eggs only much later without ever re-mating later in life, the level of intersexual conflict is extremely low and males do not benefit from decreasing the lifespan of their mates $[38,39]$. Indeed, though sperm storage might be associated with costs for queens during the early founding phase [14], mating itself appears to prolong the lifespan of queens. Queens of C. obscurior mated to males that were sterilized by irradiation laid unfertilized eggs and produced males at a similar rate as virgin queens, but lived as long as queens mated to fertile males and significantly longer than virgin queens [9]. Obviously, the physiology of queens changes in response either to the mating act itself or to the transferred seminal fluids in a way which increases their lifespan [40]. The details remain to be elucidated. The observation that, compared to virgin queens, mated honey bee queens have higher catalase activity in their spermathecae and the stored sperm [41] and an elevated expression of antioxidants in the surrounding tissues [42] might point towards a role of seminal fluids in protection against oxidative damage (see below) in addition to their obvious function of keeping sperm cells viable throughout the queen's life.

In addition, reproduction appears to increase lifespan by its own, without mating. In the queenless ant Diacam$m a$ sp., all workers are potentially capable of mating and laying fertilized eggs. The first new workers that eclose after an old reproductive has died or been removed, becomes socially dominant, mates, lays eggs, and outlives all other workers even in laboratory colonies without predation and without exhaustingly long foraging distances. If the $\alpha$-worker is not allowed to mate, it lays unfertilized, male-destined eggs, but its lifespan is nevertheless significantly longer than those of all non-reproductive nest mates [7]. Similarly, unmated workers of the clonal ant Platythyrea punctata, which produce female offspring through thelytokous parthenogenesis (i.e., the production of daughters from unfertilized eggs), live significantly longer than their non-reproductive clones [8]. As will be shown below, reproduction and aging appear to be proximately controlled by the same mechanisms. The positive association between substances that increase fecundity, immune response, and protection against oxidative substance might essentially mean that lifespan is correlated with egg-laying rate. Queens of insufficient egg-laying rate may be killed by workers [33], but to our knowledge it has not yet been investigated whether low fertile queens die earlier of innate causes. The above-mentioned observation that queens in polygynous societies lay fewer eggs and live less long than queens in monogynous societies of the same species might be of interest in this context.

\section{Juvenile Hormone and Vitellogenin Are Involved in Aging}

Social insects are still rather exotic model systems in aging research. Studies on the proximate mechanisms underlying aging and in particular the striking differ- 
ence between the lifespans of queens and workers therefore to some extent lag behind research on senescence in other animals, such as mice, Drosophila, or Caenorhabditis elegans. The advantage of such a late start is that social insect researchers can in principle build on findings from other organisms and search for analogous mechanisms in their own study objects.

For example, there is ample evidence that aging is proximately linked to oxidative damage, as suggested by the free radical hypothesis of aging [43], and that an elevation in antioxidant levels can increase the lifespan of an individual. Treating Caenorhabditis with a mimetic with superoxide dismutase (SOD) activity and the overexpression of SOD in Drosophila were both associated with longer lifespans $[44,45]$. The search for a similarly pronounced role of SOD in perennial social insects has been disappointing. Queens of the ant Lasius niger had a lower level of $\mathrm{Cu} / \mathrm{Zn} \mathrm{SOD}$ than short-lived workers and males [46], and antioxidant enzyme activities in non-reproductive tissues as, e.g., hemolymph, mid gut, and muscles, and the expression levels of genes coding for such enzymes were found to be equal in queens and workers of honey bees [41, 47]. Both results might reflect a lower rate of production of oxygen radicals in the mitochondria of long-lived animals [48], i.e., the extension of lifespan might have evolved through a decreased generation of reactive oxygen radicals rather than through an increased expression of antioxidant enzymes. Furthermore, the cell membranes of queens contain more monounsaturated and less polyunsaturated fatty acids than those of worker bees and are thus probably more resistant to oxidative damage [49].

A second important mechanism involved in aging in model organisms is the insulin/insulin-like signaling (IIS) pathway, a highly conserved signal transduction pathway which, among others, regulates fertility, metabolic rate, oxidative stress resistance, and lifespan from nematodes to vertebrates $[50,51]$. Mutant flies and mice with a deficient IIS pathway exhibited increased oxidative stress tolerance and dramatically extended lifespans. The IIS pathway controls, among other things, the expression of genes encoding the egg yolk precursor protein vitellogenin [52], a protein that is known to be of fundamental importance in caste differentiation, reproduction, and apparently also in aging. In solitary insects, vitellogenin is positively correlated with juvenile hormone [53], and the titers of both substances are usually higher in egg-laying than non-reproductive individuals [54]. In perennial social insects, the interplay between juvenile hormone, reproduction, and vitellogenin appears to be reversed: a high juvenile hormone titer shuts down the production of vitellogenin and vice versa [55-58]. Vitellogenin is synthesized at high levels in the fat bodies of honey bee queens, nurses, and overwintering workers, but when a worker becomes a forager, the vitellogenin level decreases $[57,59]$ while the juvenile hormone level increases [60]. Hence, workers begin to forage when the production of vitellogenin is experimentally impaired [61], and conversely, the hemolymph vitellogenin titer increases again and the $\mathrm{JH}$ titer drops when foragers are forced to revert to work in the hive [62]. Several studies suggest that a similar association between caste, task, vitellogenin, and juvenile hormone titers exists in ants $[63,64]$.

How do vitellogenin and juvenile hormone proximately control senescence in social insects? Vitellogenin appears to function as an antioxidant and might thus be responsible for differences in queen and worker lifespan in the honey bee [55]. Furthermore, vitellogenin also affects the immune system [19]. High juvenile hormone titers in honey bee foragers lead to the termination of vitellogenin synthesis [57], which in turn results in a decrease in the number of functional immune cells [19], and the experimental application of juvenile hormone induces hemocyte death by apoptosis $[65,66]$.

\section{Males of Social Hymenoptera Are Short-Lived}

Whereas the kings of termites appear to be as longlived as the queens [3], males of social Hymenoptera suffer a different fate. They do not actively take part in the social interactions in the nest and only function as sperm suppliers for the fertilization of the eggs laid by the queens. Already before males are sexually mature, their testes begin to degenerate and their limited sperm stores suffice only to inseminate one or a few females, after which the males die. With a few exceptions, males live only for a few days, though their sperm lives on in the queen's spermatheca in an extreme form of posthumous partner commitment [38, 39]. Some males of the ant genus Cardiocon$d y l a$ are wingless and territorial and fight to obtain a harem of virgin queens with whom they mate. In contrast to all other studied social Hymenoptera, spermatogenesis continues in these fighter males [67] and they are also considerably more long-lived than other ant males. In one extreme case, males have been observed to survive and monopolize matings for more than a year [68]. This documents that under appropriate selection pressure the lifespan of males can be surprisingly long. In contrast to females, it appears that males show the negative tradeoff 
between reproductive effort and lifespan normally found in animals [5, 6]. C. obscurior males that did not have access to queens lived significantly longer than males that were allowed to mate with several queens per day [unpublished data].

Because their lifespans are drastically shorter than those of workers and queens, males of social Hymenoptera make a particularly good system to compare the mechanisms underlying varying senescence in the different sexes. Males of L. niger have significantly shorter telomeres than queens and workers, which supports the hypothesis that telomere length might play a role in the determination of lifespan [69].

\section{Open Questions}

Our current understanding of the pattern of aging in social insects suffers from two fundamental weaknesses: a severe lack of information on the population-wide distribution of longevities and to some extent also a lack of comprehensive theories of aging which take both population dynamics and kin effects into account. With the notable exception of honey bees, most research on aging and senescence in social insects has as yet focused on just one single trait: maximum lifespan. This can only serve as the starting point for more complete investigations that include rate and source of age-specific mortality, rate of age-specific reproduction, decline of performance, and other vital demographic information. Because of their long life and the lack of methods to reliably determine the age of individuals, social insects are not a handy system for such a study in the field, but laboratory research alone will not help to answer all questions about the ultimate causes of variation in longevity.

Though first syntheses have been made, the interrelations between kin selection and the pattern of aging still need to be examined in more detail. In addition, as pointed out by Orzack [70], most present evolutionary theories of aging do not include the effects of population growth which, however, may be of importance when considering differences in the life expectancy of queens between monogynous and polygynous species. Detailed empirical and also theoretical studies on the interrelations between variation in life history and longevity among several closely related taxa of social insects are therefore needed. The ant genus Cardiocondyla, with its large variation in colony structures, the relatively short lifespans of queens and the often extremely long lifespans of males, might be found to be a valuable model system for such research.

\section{References}

1 Hölldobler B, Wilson EO: The Ants. Cambridge, Harvard University Press, 1990.

$\checkmark 2$ Keller L, Genoud M: Extraordinary lifespan in ants: a test of evolutionary theories of age ing. Nature 1997;389:958-960.

$\checkmark 3$ Keller L: Queen lifespan and colony characteristics in ants and termites. Insectes Soc 1998;45:235-246

4 Carey JR: Demographic mechanisms for the evolution of long life in social insects. Exp Gerontol 2001;36:713-722.

5 Stearns SC: The Evolution of Life Histories. Oxford, Oxford University Press, 1992.

6 Bell PD, Koufopanou V: The cost of reproduction; in Dawkins R (ed): Oxford Surveys of Evolutionary Biology. Oxford, Oxford University Press, 1985, pp 83-131.

$\checkmark 7$ Tsuji K, Nakata K, Heinze J: Ants, age and reproduction. Naturwissenschaften 1996; 83:577-578

8 Hartmann A, Heinze J: Lay eggs, live longer: Division of labor and life span in a clonal ant species. Evolution 2003;57:2424-2429.

$\checkmark 9$ Schrempf A, Heinze J, Cremer S: Sexual cooperation: mating increases longevity in ant queens. Curr Biol 2005; 15:267-270.

10 Rose MA: Evolutionary Biology of Aging. Oxford, Oxford University Press, 1991.
11 Williams PD, Day T, Fletcher Q, Rowe L: The shaping of senescence in the wild. Trends Ecol Evol 2006;21:458-463.

12 Le Bourg E: Evolutionary theories of aging handle with care. Gerontology 1998;44:345348.

13 Keller L, Genoud M: Evolutionary theories of aging. 1. The need to understand the process of natural selection. Gerontology 1999; 45:336-338.

14 Baer B, Armitage S, Boomsma JJ: Sperm stor age induces an immunity cost in ants. Nature 2006;441:872-875.

15 Neukirch A: Dependence of the life span of the honeybee (Apis mellifera) upon flight performance and energy consumption. I Comp Physiol 1982;146:35-40.

$>16$ Schmid-Hempel P, Schmid-Hempel R: Life duration and turnover of foragers in the ant Cataglyphis bicolor (Hymenoptera, Formicidae). Insectes Soc 1984;31:345-360.

17 Tofilski A: Influence of age polyethism on longevity of workers in social insects. Behav Ecol Sociobiol 2002;51:234-237.

18 Rueppell O, Bachelier C, Fondrk MK, Page RE Jr: Regulation of life history determines lifespan of worker honey bees (Apis mellifera L.). Exp Gerontol 2007;42:1020-1032.
19 Amdam GV, Simões ZLP, Hagen A, Norberg K, Schrøder K, Mikkelsen O, Kirkwood TBL, Omholt SW: Hormonal control of the yolk precursor vitellogenin regulates immune function and longevity in honeybees. Exp Gerontol 2004;39:767-773

20 Omholt SW, Amdam GV: Epigenetic regulation of aging in honeybee workers. Sci Aging Knowl Environ 2004;26:pe28.

-21 Remolina SC, Hafez DM, Robinson GE, Hughes KA: Senescence in the worker honey bee Apis mellifera. J Insect Physiol 2007;53: 1027-1033.

-22 Amdam GV, Aase ALTO, Seehuus SC, Fondrk MK, Norberg K, Hartfelder K: Social reversal of immunosenescence in honey bee workers. Exp Gerontol 2005;40:939-947.

23 Rueppell O, Christine S, Mulcrone C, Groves $\mathrm{L}$ : Aging without functional senescence in honey bee workers. Curr Biol 2007;17:R274R275.

24 Moroń D, Witek M, Woyciechowski M: Division of labour among workers with different life expectancy in the ant Myrmica scabrinodis. Anim Behav, in press. 
25 Woyciechowski M, Kozlowski J: Division of labor by division of risk according to worker life expectancy in honey bee (Apis mellifera L.). Apidologie 1998;29:191-205.

26 Chapuisat M, Keller L: Division of labour influences the rate of ageing in weaver ant workers. Proc R Soc Lond B 2002;269:909913.

-27 Camargo RS, Forti LC, Lopes JFS, Andrade APP, Ottati ALT: Age polyethism in the leafcutting ant Acromyrmex subterraneus brunneus, 1911 (Hym., Formicidae). J Appl Entomol 2007;131:139-145.

28 Schrempf A, Heinze J: Back to one: consequences of derived monogyny in an ant with polygynous ancestors. J Evol Biol 2007;20: 792-799.

29 Hölldobler B, Wilson EO: The number of queens: an important trait in ant evolution. Naturwissenschaften 1977;64:8-15.

-30 Tsuji K, Tsuji N: Evolution of life history strategies in ants: variation in queen number and mode of colony founding. Oikos 1996; 76:83-92.

31 Tsuji K: Life history strategy and evolution of insect societies: age structure, spatial distribution and density dependence; in Kipyatkov VE (ed): Social Insects: Behaviour, Ecology and Evolution. St. Petersburg, St. Petersburg University Press, 2006, pp 2136.

32 Dytham C, Travis JMJ: Evolving dispersal and age at death. Oikos 2006;113:530-538.

-33 Bourke AFG: Kin selection and the evolutionary theory of aging. Annu Rev Ecol Evol Syst 2007;38:103-128.

- 34 Keller L, Passera L, Suzzoni JP: Queen execution in the Argentine ant Iridomyrmex humilis (Mayr.). Physiol Entomol 1998;14:157163.

-35 Heinze J, Lipski N, Hölldobler B: Reproductive competition in colonies of the ant Leptothorax gredleri. Ethology 1992;90:265-278.

- 36 Dammann P, Burda H: Sexual activity and reproduction delay ageing in a mammal. Curr Biol 2006;16:R117-R118.

37 Arnqvist G, Rowe L: Sexual Conflict. Princeton, Princeton University Press, 2005.

38 Promislov D: Mate choice, sexual conflict, and evolution of senescence. Behav Genet 2003;33:191-201.

-39 Boomsma JJ, Baer B, Heinze J: The evolution of male traits in social insects. Annu Rev Entomol 2005;50:395-420.

40 Richard FJ, Tarpy DR, Grozinger CM: Effects of insemination quantity on honey bee queen physiology. PLoS ONE 2007;2:e980.

41 Weirich GF, Collins AM, Williams VP: Antioxidant enzymes in the honey bee, Apis mellifera. Apidologie 2002;33:3-14.

42 Collins AM, Williams V, Evans JD: Sperm storage and antioxidative enzyme expression in the honeybee, Apis mellifera. Insect Mol Biol 2004;13:141-146.

43 Harman D: Aging - a theory based on freeradical and radiation chemistry. J Gerontol 1956;11:298-300.
44 Melov S, Ravenscroft J, Malik S, Gill MS, Walker DW, Clayton PE, Wallace DC, Malfroy B, Doctrow SR, Lithgow GJ: Extension of life-span with superoxide dismutase/catalase mimetics. Science 2000;289:1567-1569.

45 Sun J, Molitor J, Tower J: Effects of simultaneous over-expression of $\mathrm{Cu} / \mathrm{Zn} \mathrm{SOD}$ and MnSOD on Drosophila melanogaster life span. Mech Ageing Dev 2004;125:341-349.

46 Parker JD, Parker KM, Sohal BH, Sohal RS, Keller L: Decreased expression of Cu-Zn superoxide dismutase 1 in ants with extreme lifespan. Proc Natl Acad Sci USA 2004;101: 3486-3489.

47 Corona M, Hughes KA, Weaver DB, Robinson GE: Gene expression patterns associated with queen honey bee longevity. Mech Ageing Dev 2005;126:1230-1238.

48 Perez-Campo R, Torres-Lopez M, Cadenas E, Rojas C, Barja G: The rate of free radical production as a determinant of the rate of aging: evidence from the comparative approach. J Comp Physiol 1998;168:149-158.

49 Haddad LS, Kelbert L, Hulbert AJ: Extended longevity of queen honey bees compared to workers is associated with peroxidation-resistant membranes. Exp Gerontol 2007;42: 601-609.

50 Guarante L, Kenyon C: Genetic pathways that regulate ageing in model organisms. $\mathrm{Na}$ ture 2000;408:255-266

51 Crown A, Clifton DK, Steiner RA: Neuropeptide signalling in the integration of metabolism and reproduction. Neuroendocrinology 2007;86:175-182.

52 Amdam GV, Nilsen K-A, Norberg K, Fondrk MK, Hartfelder K: Variation in endocrine signalling underlies variation in social lifehistory. Am Nat 2007;170:37-46.

53 Riddiford LM: Cellular and molecular actions of juvenile hormone I. General considerations and premetamorphic actions. Adv Insect Physiol 1994;24:213-274.

54 Byrne BM, Gruber M, Ab G: The evolution of egg yolk proteins. Prog Biophysiol Mol Biol 1989;53:33-69.

55 Seehuus SC, Norberg K, Gimsa U, Krekling T, Amdam GV: Reproductive protein protects sterile honey bee workers from oxidative stress. Proc Natl Acad Sci USA 2006;103: 962-967.

56 Amdam GV, Omholt SW: The hive bee to forager transition in honeybee colonies: the double repressor hypothesis. J Theor Biol 2003;223:451-464.

57 Pinto LZ, Bitondi MMG, Simões ZLP: Inhibition of vitellogenin synthesis in Apis mellifera workers by a juvenile hormone analogue, pyriproxyfen. J Insect Physiol 2000; 46:153-160.

58 Guidugli KR, Nascimento AN, Amdam GV, Barchuk AR, Omholt SW, Simões ZLP, Hartfelder K: Vitellogenin regulates hormonal dynamics in the worker caste of a eusocial insect. FEBS Lett 2005;579:4961-4965.
59 Engels W, Kaatz H, Zillikens A, Simoes A, Trube A, Braun R, Dittrich F: Honey bee reproduction: vitellogenin and caste-specific regulation of fertility. Adv Invertebr Reprod 1990;5:495-502.

60 Fluri P, Lüscher H, Wille H, Gerig L: Changes in weight of the pharyngeal gland and haemolymph titres of juvenile hormone, protein and vitellogenin in worker honey bees. J Insect Physiol 1982;26:61-68.

61 Nelson CM, Ihle K, Fondrk MK, Page RE Jr, Amdam GV: The gene vitellogenin has multiple coordinating effects on social organization. PLoS Biol 2007;5:673-677.

62 Huang ZY, Robinson GE: Regulation of honey bee division of labor by colony age demography. Behav Ecol Sociobiol 1996;39:147158.

63 Gräff J, Jemielity S, Parker JD, Parker KM, Keller L: Differential gene expression between adult queens and workers in the ant Lasius niger. Mol Ecol 2007;16:675-683.

64 Tian HS, Vinson SB, Coates CJ: Differential gene expression between alate and dealate queens in the red important fire ant, Solenopsis invicta Buren (Hymenoptera: Formicidae). Insect Biochem Mol Biol 2004;34: 937-949.

65 Rutz W, Gerig L, Wille H, Lüscher H: A bioessay for juvenile hormone (JH) effects on insect growth regulators (IGR) on adult worker honeybees. Bull Soc Entomol Suisse 1974;47:307-313.

66 Wille H, Rutz W: Beziehungen zwischen Juvenilhormontiter und Hämozyten erwachsener Sommerbienen (Apis mellifera L.). Schweiz Landwirtschaft Forsch 1975; 14: 339-353.

67 Heinze J, Hölldobler B: Fighting for a harem of queens: physiology of reproduction in Cardiocondyla male ants. Proc Natl Acad Sci USA 1993;90:8412-8414.

68 Yamauchi K, Ishida Y, Hashim R, Heinze J: Queen-queen competition by precocious male production in multi-queen ant colonies. Curr Biol 2006;16:2424-2427.

69 Jemielity S, Kimura M, Parker KM, Parker JD, Cao X, Aviv A, Keller L: Short telomeres in short-lived males: what are the molecular and evolutionary causes? Aging Cell 2007;6: 225-233.

70 Orzack SH: How and why do aging and life span evolve? Pop Dev Rev 2003;29S:19-38.

71 Medawar PB: An Unsolved Problem of Biology. London, Lewis HK, 1952.

72 Williams GC: Pleiotropy, natural selection, and the evolution of senescence. Evolution 1957; 11:398-411.

73 Kirkwood TBL: Evolution of ageing. Nature 1977;270:301-304.

74 Kirkwood TBL: Repair and its evolution: survival versus reproduction; in Townsend C, Calow P (eds): Physiological Ecology: An Evolutionary Approach to Resource Use. Oxford, Blackwell Scientific, 1981, pp 165189. 